\title{
Update on the Global Prevalence of Severe Fear of Childbirth in Low-Risk Pregnant Women: A Systematic Review and Meta-Analysis
}

\author{
Shahrzad Sanjari $^{1 \oplus}$, Reza Chaman $^{2}{ }^{\circledR}$, Shahrbanoo Salehin $^{3}{ }^{\circledR}$, Shahrbanoo Goli $^{4^{\oplus}}$, Afsaneh Keramat $^{* *}$
}

\begin{abstract}
Objectives: Severe fear of childbirth (FOC) has adverse consequences for mother and child. This study aimed to update the global prevalence of severe FOC in low-risk pregnant women.

Materials and Methods: Observational studies published in English were obtained through PubMed, Scopus, Science Direct, Wiley Online, and Google Scholar databases up to April 2020. After reviewing the title and introduction, the quality of the articles that had full text and met the inclusion criteria of the study was checked with the JBI checklist. Then, the final extracted data were entered into the STATA software. The overall prevalence of severe FOC and fear in subgroups were obtained using meta-analysis. Tests of publication bias and sensitivity analysis were also performed.

Results: Overall, 27 observational studies were included (26014 participants). The global prevalence of severe FOC was 16\% (95\% Cl: $14 \%-19 \%)$. The subgroup analysis showed that after 2015, the prevalence of fear was higher than before (\%18 versus \%14). The results also showed a higher prevalence of fear in women with a diploma and lower compared to women with a university education (\%19 versus \%13), in single/divorced women compared to married/cohabitation women (\%21 versus \%15), in nulliparous women compared to multiparous women (\%17 versus \%14) and in women experiencing the second trimester of pregnancy compared to women in the third trimester of pregnancy (\%23 versus \%14).

Conclusions: The global prevalence of severe FOC was $16 \%$. Diagnostic, preventive, therapeutic and follow-up strategies are needed to reduce fear in all countries.

Keywords: Fear of childbirth, Pregnancy, Prevalence, Meta-analysis
\end{abstract}

\section{Introduction}

Pregnancy and delivery procedures are physiological processes $(1,2)$, but these procedures are so distressing for some women that generate fear of childbirth (FOC) (3). FOC is a multifaceted variable that encompasses a wide range of indicators from negative feelings about childbirth to fears such as fear of pain, fear of medical interventions, fear of loss of independence, fear of staff misconduct, fear of maternal and infant death, fear of injury, fear of body change, and fear of unemployment and poverty (3-12).

FOC varies from mild to severe (10). According to estimates obtained from previous studies, the prevalence of FOC is between 5 and 21\% (13); however, about $10 \%$ of women fear is so severe that it leads to women dysfunction, negative birth consequences, unpleasant experiences of childbirth, desire for cesarean section, emergency cesarean section, or even avoidance of pregnancy (14-19). The cesarean section increases the risk of complications of anesthesia, embolism, adhesions, persistent pain, ectopic pregnancy, stillbirth, uterine rupture, infertility and hysterectomy in mother and urinary tract infections, obesity, asthma and diabetes type 1 in the child (20-22). Avoiding pregnancy can reduce the replacement rate (23).

Demographic and obstetrics factors have a major effect on the severity of FOC (24) but this effect is ambiguous in studies. The prevalence of fear is higher among women who are younger (25), low-educated (26-28), single/ divorced $(27,29)$, and unemployed $(11,26)$. However, some studies have reported conflicting findings (28,30-32). Fear is more common in women who expect their first child (nulliparous women) $(13,29,33,34)$. However, different result was reported based on Nieminen's study indicating that women with childbirth experience (multiparous women) were more afraid (35). Although the prevalence of fear is generally believed to be higher in the third trimester, it has not been proven yet (24).

The discrepancies in the studies are due to differences in culture, financial worries, and available tools $(24,36)$. It seems that in some scales, financial and cultural indicators of FOC have led to different results (37), which can be 
Key Messages

- Sever Fear of Childbirth (FOC) has negative consequences for mother and child. It also increases pregnancy avoidance.

- Since the number of studies investigating the prevalence of FOC has increased recently, performing the meta-analysis can have scientific and practical benefits.

- The prevalence of Sever FOC has increased since 2015, but this prevalence varies according to education, marital, parity, and trimester status.

avoided by using those scales that do not measure these indicators. One of these scales is the Wijma Childbirth Expectancy Scale (W-DEQ), which is one of the most widely used measures to measure the FOC. The W-DEQ contains questions about women's feelings and emotions about childbirth (38). Given that fear is an emotion (39), this scale is the best tool for measuring FOC.

On the other hand, most researchers agree on increasing FOC in women $(33,40,41)$, while some other researchers disagree with this assumption (42). Performing a metaanalysis on the overall prevalence of FOC removes the existing ambiguities and can help planners and researchers to use appropriate interventions to prevent or reduce this fear. A meta-analysis on the overall prevalence of FOC was conducted in 2016. Since then, several studies have been conducted to examine the prevalence of FOC. This makes the results of the recent meta-analysis obsolete. Therefore, this study was carried out to update the meta-analysis of the studies that measured the prevalence of sever FOC using W-DEQ-A.

\section{Methods}

This meta-analysis was conducted in accordance with the PRISMA guidelines for reporting systematic reviews and meta-analysis (43-45).

\section{Search Strategy}

Five electronic databases (PubMed, Google Scholar, Science Direct, Scopus, and Wiley online) were selected and searched for all published literature on the given topic up to 19 April 2020 using keywords "fear of birth", "fear of childbirth", "fear of labor", "fear of pregnancy" and "tocophobia".

\section{Selection of Studies}

Inclusion criteria: observational studies published in English using WDEQ-A to measure the prevalence of severe FOC in pregnant women at any age, and in each trimester of pregnancy. Exclusion criteria: Experimental/ quasi-experimental or review studies not providing full texts or not reporting sufficient data to calculate the prevalence of fear. Two researchers (First anf third authors) reviewed the titles and abstracts of the studies based on inclusion and exclusion criteria. Then, they assessed the validity of the remaining articles. Finally, the following data including author, year of publication, country of study, study design, sample size, and prevalence were extracted from the full texts of the selected articles.

\section{Instrument}

The applied tool was the 33-item W-DEQ-A, which is a 6-point Likert-type scale. The scores ranged from 0 to 165. Scores of 85 and above were indicative of a Severe FOC and were considered in this study (46).

\section{Methodological Quality Assessment}

Two researchers assessed the quality of the studies separately using the JBI Critical Appraisal Checklist for Analytical prevalence Studies published by the Joanna Briggs Institute (47), which comprises nine questions. The answer to each question is in one of four modes: yes, no, unclear, and not applicable. Scoring is 1 point for "yes", and 0 point for "the rest of the answers". We only included high-quality articles (score of $\geq 5$ out of 9 ) in this review.

If there was a dispute between two researchers on data extraction or qualitative evaluation of studies, the viewpoint of the third researcher was adopted.

\section{Statistical Analysis}

To estimate the pooled prevalence of severe FOC, a metaanalysis was conducted using STATA software (version 21) and the fixed or random-effects model. Cochran's $Q$ test and $\mathrm{I}^{2}$ index were used to examine the heterogeneity of studies. We used a random-effect model for heterogeneity above $75 \%$ (48). The FOC at severe levels was described as the W-DEQ-A score of 85 points and above. Sensitivity analysis was performed to assess the role of each study on the overall prevalence of Severe FOC.

Subgroup analyses were conducted based on the year of publication (up to 2015 vs. since 2015), education (diploma and less vs. university), marital status (married/ cohabitation vs. single/divorced), parity (nulliparous women vs. multiparous women), and trimester of pregnancy (second trimester vs. third trimester). The publication bias was evaluated by Begg's test. A significance level of less than 0.05 revealed the publication bias (49).

\section{Results}

Through the initial search, a total of 1207 articles were detected, 628 of which were deleted due to being duplicate. After removing unrelated studies, 93 full-text articles were assessed for eligibility, where 27 studies met the eligibility criteria for meta-analysis (Figure 1). A total of 26014 women were included in the study (Minimum sample $=137$, Maximum sample $=6870)(27,50)$. Summary characteristics of studies are shown in Table 1.

\section{Publication Bias}

According to Begg's test $(P=0.8)$, there was no publication bias. 


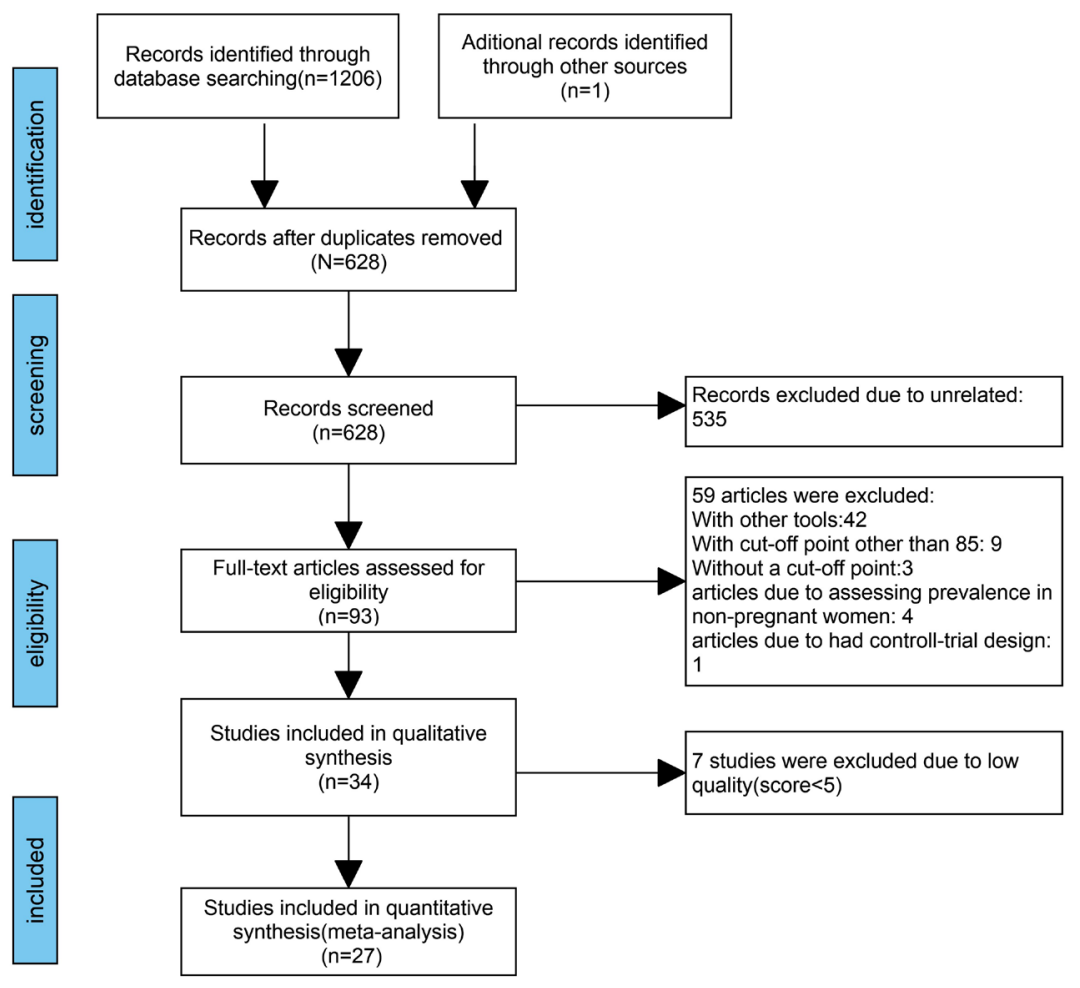

Figure 1. The Flowchart on the Stages of Including the Studies in the Systematic Review and Meta-Analysis.

Table 1. Characteristics of Included Studies on Sever FOC

\begin{tabular}{|c|c|c|c|c|c|}
\hline First Author (year) & Country & Study Design & Sample Size & Prevalence & Score of Quality \\
\hline Adams (2012) & Norway & Cohort & 2206 & $7.5 \%$ & 8 \\
\hline Aksoy (2014) & Turkey & Cross-sectional & 900 & $16.1 \%$ & 9 \\
\hline Aksoy (2016) & Turkey & Cross-sectional & 350 & $11.4 \%$ & 6 \\
\hline Aligani (2019) & Iran & Cross-sectional & 211 & $22.7 \%$ & 7 \\
\hline Çapik (2018) & Turkey & Cross-sectional & 301 & $6.6 \%$ & 6 \\
\hline Çıtak Bilgin (2020) & Turkey & Cross-sectional & 624 & $20.8 \%$ & 8 \\
\hline Henriksen (2018) & Norway & Cohort & 2145 & $12 \%$ & 9 \\
\hline Jokić- Begić (2013) & Hungary & Cohort & 200 & $11.5 \%$ & 6 \\
\hline Klabbers (2018) & Netherland & & 484 & $27.6 \%$ & 5 \\
\hline Korukcu (2010) & Turkey & Cross-sectional & 660 & $0.9 \%$ & 5 \\
\hline Korukcu (2018) & Turkey & Cross-sectional & 309 & $19.1 \%$ & 5 \\
\hline Lukasse (2014) & Six european countries & Cross-sectional & 6870 & $11 \%$ & 8 \\
\hline Mildren (2018) & United States & & 137 & $39.4 \%$ & 5 \\
\hline Mortazavi (2018) & Iran & Cross-sectional & 522 & $19.6 \%$ & 8 \\
\hline Nieminen (2009) & Sweden & Cross-sectional & 1635 & $15.6 \%$ & 9 \\
\hline O'Connell (2019) & Ireland & Cross-sectional & 882 & $5.3 \%$ & 8 \\
\hline Okumus (2017) & Turkey & Cross-sectional & 253 & $54 \%$ & 5 \\
\hline Onchonga (2020) & Kenya & Cross-sectional & 376 & $8 \%$ & 8 \\
\hline Phunyammale (2019) & Thailand & Cross-sectional & 305 & $0.7 \%$ & 9 \\
\hline Ryding (2008) & Sweden & Case-control & 1981 & $10 \%$ & 8 \\
\hline Salomonsson (2013) & Sweden & Cross-sectional & 423 & $20.8 \%$ & 5 \\
\hline Schroll (2011) & Denmark & Cohort & 2638 & $8.7 \%$ & 9 \\
\hline Sluijs (2019) & Netherlands & Cohort & 331 & $11 \%$ & 7 \\
\hline Tata (2019) & Iran & Cross-sectional & 230 & $12.6 \%$ & 7 \\
\hline Toohill (2014) & Australian & Cross-sectional & 1386 & $4.8 \%$ & 9 \\
\hline Wiklund (2007) & Sweden & Cohort & 496 & $17 \%$ & 7 \\
\hline Zar (2002) & Sweden & & 506 & $11 \%$ & 8 \\
\hline
\end{tabular}


Meta-analysis

The pooled prevalence of severe FOC in 27 final studies with a random-effects model was 16\% (95\% CI: $14 \%$ $19 \%)$; and $\mathrm{I}^{2}$ test result showed high heterogeneity $\left(\mathrm{I}^{2}=\right.$ 98.1\%, $P=0.00$ ) (Figure 2).

The results of the sensitivity analysis revealed - in the absence of each study, no substantial change in the overall prevalence of severe FOC. The range of change was between 15\% (95\% CI: 13-17\%), with Korukcu et al (51), Okumus et al (52), and Mildren et al (50) excluded; and 17\% (95\% CI: 14-19\%), with Toohill et al (24), O'Connell et al (13), and Phunyammalee et al (28) excluded.

Subgroup Analyses Based on Year of Publication

Fifteen studies estimated the prevalence of severe fear since 2015, and twelve studies estimated the prevalence of severe fear up to 2015. The pooled prevalence was 18\% (95\% CI: $13 \%-23 \%)$ and 14\% (95\% CI: $11 \%-17 \%)$ respectively. Heterogeneity of studies was significant $\left(\mathrm{I}^{2}=\right.$ 98.1\%, $P=0.00$ ) (Figure 3).

Subgroup Analyses Based on Education

Six studies assessed the prevalence of severe FOC based on education level. We divided the data related to education into two categories: diploma and less, and university level. The pooled prevalence of severe fear was 19\% (95\% CI: 16\%-21\%) and 13\% (95\% CI: 10\%-16\%) respectively. Heterogeneity of studies was high in both categories $\left(\mathrm{I}^{2}=\right.$ 91.8\%, $P=0.00$ ) (Figure 4).

Subgroup Analyses Based on Marital Status

Four studies assessed prevalence in single/divorced women and the pooled prevalence was $21 \%$ (95\% CI: $12 \%$ $30 \%)$. Six studies measured the prevalence of sever fear in married/cohabitation women and the pooled prevalence

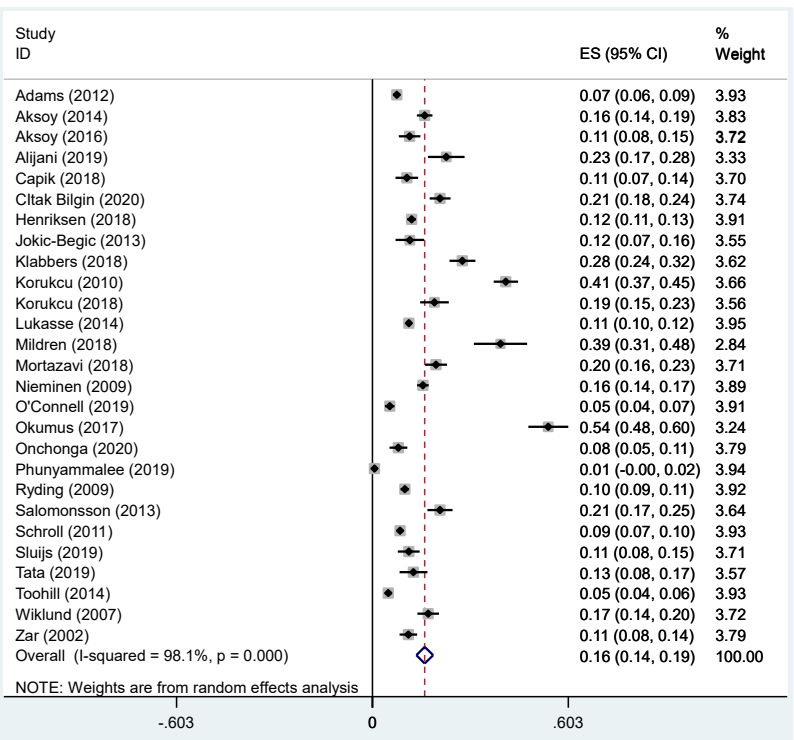

Figure 2. Forest Plot of the Meta-Analysis for the Prevalence of Severe FOC for all Studies Included in the Meta-Analysis. became $15 \%$ (95\% CI: 11\%-18\%). Heterogeneity of the studies was significant $\left(\mathrm{I}^{2}=95.4 \%, P=0.00\right)$ (Figure 5).

Subgroup Analyses Based on Parity

Sixteen studies estimated the pooled prevalence of severe FOC in nulliparous women and thirteen studies estimated the prevalence of severe FOC in multiparous women. Using the random-effects model, the pooled prevalence was $17 \%$ (95\% CI: $14 \%-20 \%)$ and $14 \%$ (95\% CI: $11 \%-$ $17 \%)$, respectively. The heterogeneity of the studies was high $\left(\mathrm{I}^{2}=96.4 \%, P=0.00\right)$ (Figure 6).

Subgroup Analyses Based on Trimester The pooled prevalence of severe FOC was 23\% (95\% CI: $11 \%-34 \%)$ in 6 studies with data relating to the second

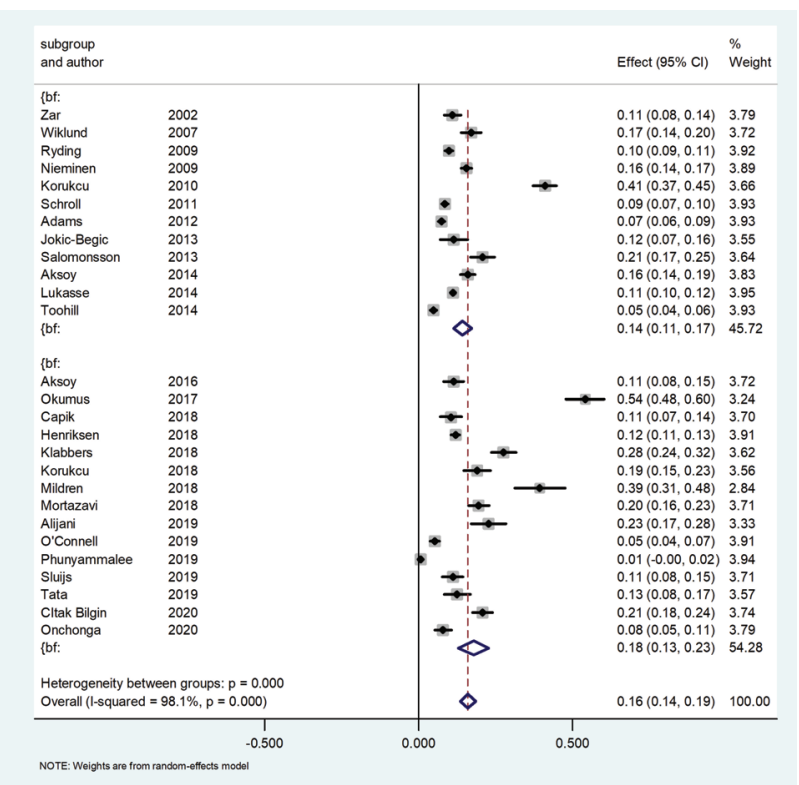

Figure 3. Forest Plot of the Meta-Analysis for the Prevalence of Severe FOC Based on Publication Date of the Studies.

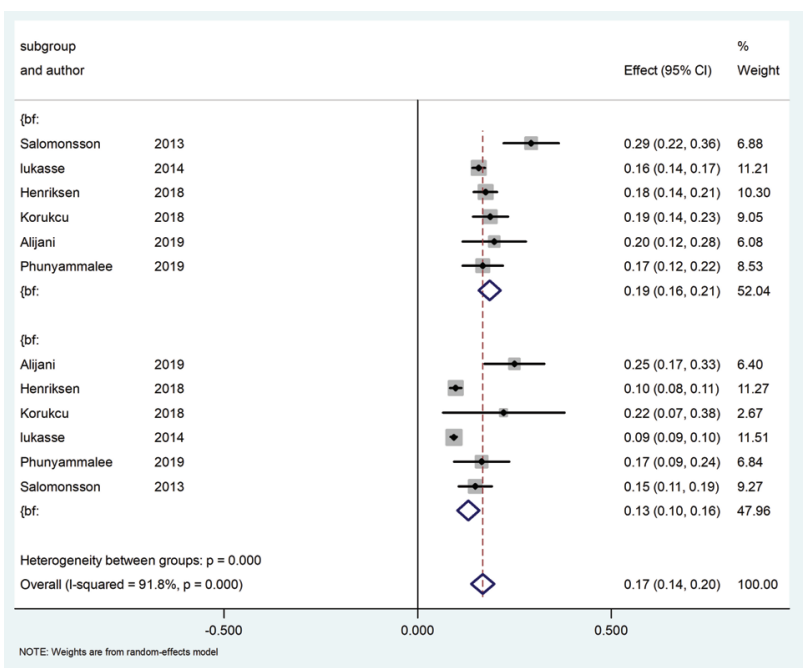

Figure 4. Forest Plot of the Meta-Analysis for the Prevalence of Severe FOC Based on the Education Level. 


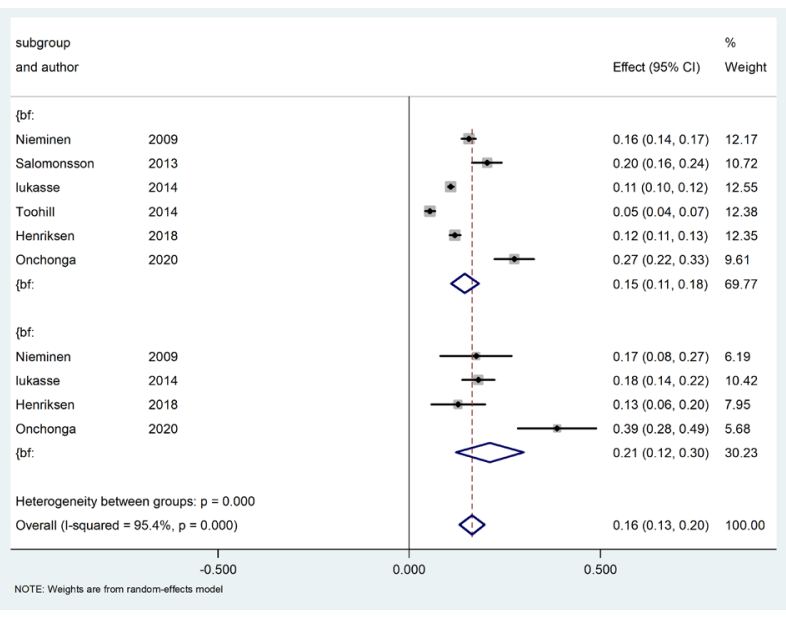

Figure 5. Forest Plot of the Meta-Analysis for the Prevalence of Severe FOC Based on Marital Status.

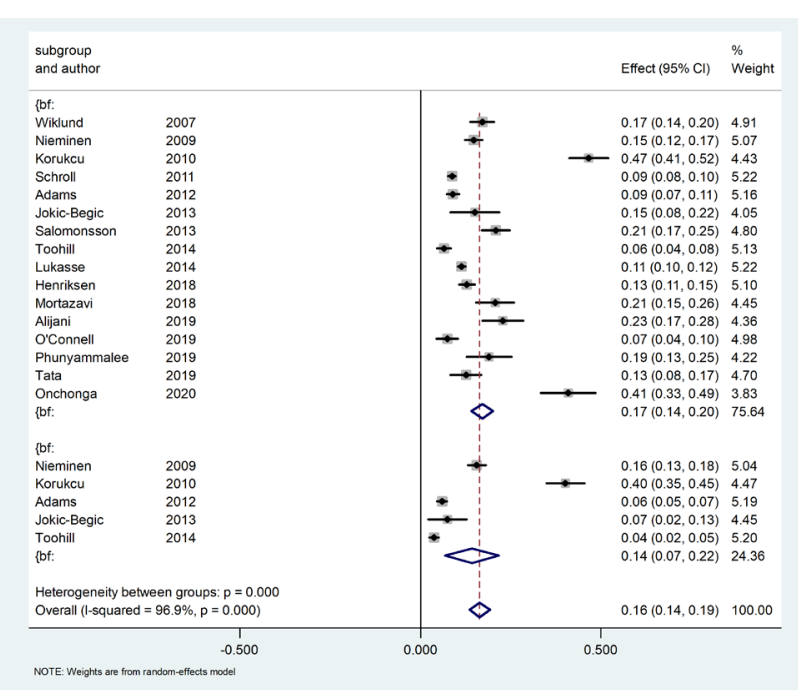

Figure 6. Forest Plot of the Meta-Analysis for the Prevalence of Severe FOC Based on Parity.

trimester (between 17 and 28 weeks of pregnancy) versus 14\% (95\% CI: 10\%-18\%) in 14 studies with data concerning the third trimester (over 28 weeks of pregnancy). Heterogeneity proved to be significant $\left(\mathrm{I}^{2}=98.3 \%, P=\right.$ $0.0)$. Seven studies were not included in the meta-analysis due to lack of clear classification $(13,27,32,33,35,50,53)$ (Figure 7).

\section{Discussion}

Severe FOC is an important public health problem all over the world. Women with severe FOC don't have sufficient ability and confidence to successfully adapt to labor and delivery, and are more likely to seek cesarean section $(26,54)$. Increasing the rate of cesarean section not only has a financial burden but also harms the health of mother and child. Therefore, the global prevalence of severe FOC in pregnant women was examined.

Based on this review, the global prevalence of severe

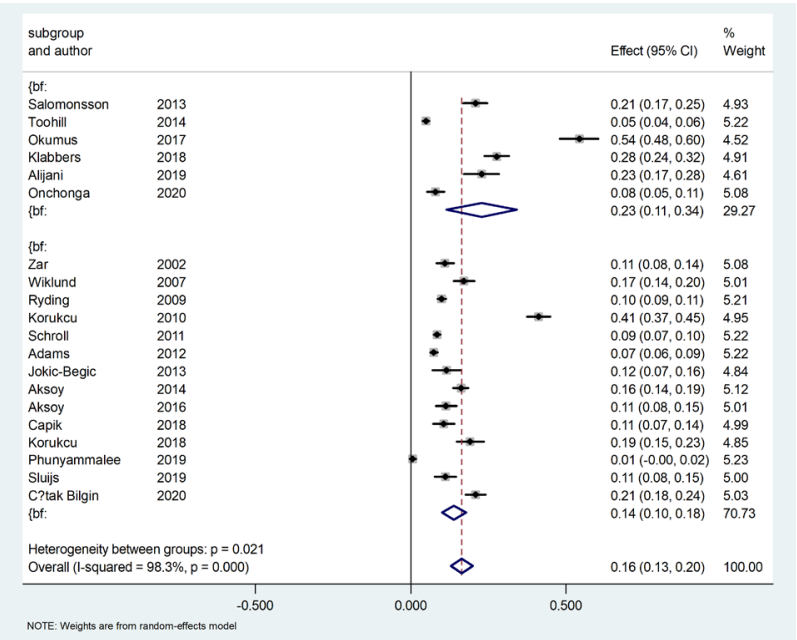

Figure 7. Forest Plot of the Meta-Analysis for the Prevalence of Severe FOC Based on the Trimester of Pregnancy.

FOC was 16\%. The findings also showed that the prevalence of fear has increased since 2015 compared to the time period before this year. In a meta-analysis study conducted by O'Connell et al in 2016, the worldwide prevalence of tocophobia was $12 \%$ in studies to have used WDEQ-A. This difference is due to the fact that in O'Connell and colleagues' review, included studies were related to developed countries, where the prevalence of fear is low; in the present review, however, both developed and developing countries were included in the metaanalysis, not ignoring the fact that developing countries have a different socio-economic, political and weaker health system. For example, in Turkey and Iran - two developing countries, issues including insufficient support from family and spouse, lack of decision making, lack of trust in staff due to a variety of health professionals within different disciplines, deficiency maternal care practices such as home visit $(47,55)$, and lack of home birth are the most important reasons for high prevalence of FOC.

In subgroup analysis, moreover, the prevalence of fear was higher in women with a diploma and lower educational degrees compared to women with academic degrees. This is similar to the findings of nine previous studies $(4,11,27,28,31,32,56-58)$ but different from the results of one previous study (55). Since providing information regarding pregnancy and birth is not commensurate with the level of education of women, those women with lower levels of education do not fully understand the information (59). On the other hand, higher education is associated with the use of more effective and adaptive coping strategies in the face of a problem, which can prevent aggravation of the problem (48).

The current study also found that single/divorced women were more likely to be afraid than those who were married/cohabitated. This finding was confirmed by the results from four studies $(4,11,56,60)$. Single/divorced 
women do not enjoy the support of their spouses. Research has shown that spouse and family support reduce FOC in pregnant women (52).

Subgroup analysis results indicated that the prevalence of fear was higher in Nulliparous women than in Multiparous women. Our findings were also confirmed by other studies $(34,50)$. However, the values obtained from our review are close to the values derived in O'Connell and colleagues' review; thus the prevalence in our study must be interpreted with caution because seven studies reported only general prevalence and did not calculate the prevalence in nulliparous and multiparous women separately. The prevalence of these studies ranged from $10 \%$ to $75 \%$. The reason behind the more amount of fear among nulliparous women lies in the fact that the labor pain, birth support, and birth experience are still unknown (61). However, there are conflicting studies showing that the prevalence of fear was higher in multiparous women $(11,35)$. One reason for this lay in the fact that the parous women had a negative experience of previous birth, and this might have increased the FOC (11).

Also, the prevalence in the second trimester of pregnancy was higher than in the third trimester of pregnancy. This result is different from the findings of four previous studies $(27,31,33,62)$. In this context, it may be stated that the statistical population relating to most of the studies examining the prevalence of fear in the second trimester were nulliparous women who, according to the findings of this study, were more afraid than multiparous women.

However, FOC is not a new phenomenon and increasing prevalence of this fear indicates that various factors, including the lack of care for women delivered by staff, unfriendly relationships between women and staff, lack of involvement of women in decision- making processes, lack of support, as well as the scanty knowledge about the birth are responsible for it (52). To reduce the FOC, therefore, a complete package including identification of women with severe fear, interventions to reduce fear, prenatal support (social support, family support, spouse support, staff support, and informational support), and postpartum monitoring are required.

\section{Strengths and Limitations}

The greatest strength of this study was the inclusion of studies that had used the WDEQ-A. Since WDEQ-A is not a multifactorial scale, its results cannot be cumulative with scales that are multifactorial. Therefore, the overall prevalence obtained from the studies that used this scale is more valid (28). In this review, one study used the electronic version of WDEQ-A without validation (50). When data are collected online, the results may be biased due to the low internet literacy of some people. Finally, we did not have enough data to calculate the overall prevalence based on age and employment status.

\section{Conclusions}

This meta-analysis helped update the overall prevalence of severe FOC in pregnant women. The results showed an increase in the prevalence of fear compared to the first meta-analysis (63). Since many studies on the prevalence of fear have been widely conducted around the world in recent years, the present review can clearly show the current prevalence of global fear. The results of this study revealed an increase in prevalence of fear since 2015. Furthermore, the amount of fear was higher among women who had lower education or were single and nulliparous. These results being significant, therefore, can be used for proper health planning.

\section{Authors' Contribution}

SHS, AK conceived of the presented idea. SHS did the literature search and, together with AK, selected the studies. SHS and SHS checked the quality of the studies. SHS and $\mathrm{RCH}$ performed the calculations and SHG confirmed them. SHS, AK, and RCH interpreted the data. SHS wrote the first draft of the paper. All the authors read the draft and provided critical feedback. All authors approved the final draft.

\section{Conflict of Interests}

Authors declare that they have no conflict of interests.

\section{Ethical Issues}

This study was approved by the Shahroud university of medical sciences ethical committee (Code: IR.SHMU.REC.1398.098).

\section{Financial Support}

The present study was supported by Shahroud University of medical sciences as a PhD Thesis. We hereby acknowledge the research deputy for grant No. 9875.

\section{Acknowledgments}

We thank Shahroud University of Medical Sciences for the financial support provided for this thesis.

\section{References}

1. Henriksen L, Grimsrud E, Schei B, Lukasse M. Factors related to a negative birth experience - a mixed methods study. Midwifery. 2017;51:33-39. doi:10.1016/j.midw.2017.05.004

2. Tugut N, Tirkes D, Demirel G. Preparedness of pregnant women for childbirth and the postpartum period: their knowledge and fear. J Obstet Gynaecol. 2015;35(4):336-340. doi:10.3109/0144 3615.2014 .960375

3. Wijma K, Wijma B, Zar M. Psychometric aspects of the W-DEQ; a new questionnaire for the measurement of fear of childbirth. J Psychosom Obstet Gynaecol. 1998;19(2):84-97. doi:10.3109/01674829809048501

4. Elvander $\mathrm{C}$, Cnattingius $\mathrm{S}, \mathrm{Kjerulff} \mathrm{KH}$. Birth experience in women with low, intermediate or high levels of fear: findings from the first baby study. Birth. 2013;40(4):289-296. doi:10.1111/birt.12065

5. Eriksson C, Westman G, Hamberg K. Experiential factors associated with childbirth-related fear in Swedish women and men: a population based study. J Psychosom Obstet Gynaecol. 2005;26(1):63-72. doi:10.1080/01674820400023275

6. Geissbuehler V, Eberhard J. Fear of childbirth during pregnancy: a study of more than 8000 pregnant women. J Psychosom Obstet Gynaecol. 2002;23(4):229-235. doi:10.3109/01674820209074677

7. Hildingsson I, Thomas J, Karlström A, Olofsson RE, Nystedt A. Childbirth thoughts in mid-pregnancy: prevalence and associated factors in prospective parents. Sex Reprod Healthc. 2010;1(2):4553. doi:10.1016/j.srhc.2009.11.003

8. Laursen M, Hedegaard M, Johansen C. Fear of childbirth: 
predictors and temporal changes among nulliparous women in the Danish National Birth Cohort. BJOG. 2008;115(3):354-360. doi:10.1111/j.1471-0528.2007.01583.x

9. Saisto T, Salmela-Aro K, Nurmi JE, Könönen T, Halmesmäki E. A randomized controlled trial of intervention in fear of childbirth. Obstet Gynecol. 2001;98(5 Pt 1):820-826. doi:10.1016/s00297844(01)01552-6

10. Striebich S, Mattern E, Ayerle GM. Support for pregnant women identified with fear of childbirth (FOC)/tokophobia - a systematic review of approaches and interventions. Midwifery. 2018;61:97115. doi:10.1016/j.midw.2018.02.013

11. Waldenström U, Hildingsson I, Ryding EL. Antenatal fear of childbirth and its association with subsequent caesarean section and experience of childbirth. BJOG. 2006;113(6):638-646. doi:10.1111/j.1471-0528.2006.00950.x

12. Nilsson C, Lundgren I, Karlström A, Hildingsson I. Self reported fear of childbirth and its association with women's birth experience and mode of delivery: a longitudinal population-based study. Women Birth. 2012;25(3):114-121. doi:10.1016/j.wombi.2011.06.001

13. O'Connell MA, Leahy-Warren P, Kenny LC, O'Neill SM, Khashan AS. The prevalence and risk factors of fear of childbirth among pregnant women: a cross-sectional study in Ireland. Acta Obstet Gynecol Scand. 2019;98(8):1014-1023. doi:10.1111/aogs.13599

14. Madhavanprabhakaran GK, D'Souza MS, Nairy KS. Prevalence of pregnancy anxiety and associated factors. Int J Afr Nurs Sci. 2015;3:1-7. doi:10.1016/j.ijans.2015.06.002

15. Klabbers GA, Wijma K, van Bakel HJ, Paarlberg KM, Vingerhoets AJ. Resistance to fear of child birth and stability of mother-child bond. Early Child Dev Care. 2020;190(2):175-184. doi:10.1080/0 3004430.2018.1461093

16. Rondung E, Thomtén J, Sundin Ö. Psychological perspectives on fear of childbirth. J Anxiety Disord. 2016;44:80-91. doi:10.1016/j. janxdis.2016.10.007

17. Abd El-Aziz NS, Mansour S, Hassan FN. Factors associated with fear of childbirth: it's effect on women's preference for elective cesarean section. J Nurs Educ Pract. 2016;7(1):133-145. doi:10.5430/jnep.v7n1p133

18. Molgora S, Fenaroli V, Cracolici E, Saita E. Antenatal fear of childbirth and emergency cesarean section delivery: a systematic narrative review. J Reprod Infant Psychol. 2020;38(4):436-454. do i:10.1080/02646838.2019.1636216

19. Aksoy M, Aksoy AN, Dostbil A, Celik MG, Ince I. The relationship between fear of childbirth and women's knowledge about painless childbirth. Obstet Gynecol Int. 2014;2014:274303. doi:10.1155/2014/274303

20. Słabuszewska-Jóźwiak A, Szymański JK, Ciebiera M, SareckaHujar B, Jakiel G. Pediatrics consequences of caesarean section-a systematic review and meta-analysis. Int J Environ Res Public Health. 2020;17(21):8031. doi:10.3390/ijerph17218031

21. Mylonas I, Friese K. Indications for and risks of elective cesarean section. Dtsch Arztebl Int. 2015;112(29-30):489-495. doi:10.3238/ arztebl.2015.0489

22. O'Neill SM, Agerbo E, Kenny LC, et al. Cesarean section and rate of subsequent stillbirth, miscarriage, and ectopic pregnancy: a Danish register-based cohort study. PLoS Med. 2014;11(7):e1001670. doi:10.1371/journal.pmed.1001670

23. Mastroianni L Jr, Donaldson PJ, Kane TT. Development of contraceptives--obstacles and opportunities. N Engl J Med. 1990;322(7):482-484. doi:10.1056/nejm199002153220732

24. Toohill J, Fenwick J, Gamble J, Creedy DK. Prevalence of childbirth fear in an Australian sample of pregnant women. BMC Pregnancy Childbirth. 2014;14:275. doi:10.1186/1471-2393-14-275

25. Hildingsson I, Haines H, Karlström A, Nystedt A. Presence and process of fear of birth during pregnancy-findings from a longitudinal cohort study. Women Birth. 2017;30(5):e242-e247. doi:10.1016/j.wombi.2017.02.003

26. Salomonsson B, Gullberg MT, Alehagen S, Wijma K. Self-efficacy beliefs and fear of childbirth in nulliparous women. J Psychosom Obstet Gynaecol. 2013;34(3):116-121. doi:10.3109/016748
$2 \times .2013 .824418$

27. Lukasse M, Schei B, Ryding EL. Prevalence and associated factors of fear of childbirth in six European countries. Sex Reprod Healthc. 2014;5(3):99-106. doi:10.1016/j.srhc.2014.06.007

28. Phunyammalee M, Buayaem T, Boriboonhirunsarn D. Fear of childbirth and associated factors among low-risk pregnant women. J Obstet Gynaecol. 2019;39(6):763-767. doi:10.1080/01443615. 2019.1584885

29. Onchonga D, MoghaddamHosseini V, Keraka M, Várnagy Á. Prevalence of fear of childbirth in a sample of gravida women in Kenya. Sex Reprod Healthc. 2020;24:100510. doi:10.1016/j. srhc.2020.100510

30. Nieminen K, Wijma K, Johansson S, et al. Severe fear of childbirth indicates high perinatal costs for Swedish women giving birth to their first child. Acta Obstet Gynecol Scand. 2017;96(4):438-446. doi:10.1111/aogs.13091

31. Moghaddam Hossieni V, Toohill J, Akaberi A, HashemiAsl B. Influence of intimate partner violence during pregnancy on fear of childbirth. Sex Reprod Healthc. 2017;14:17-23. doi:10.1016/j. srhc.2017.09.001

32. Henriksen L, Borgen A, Risløkken J, Lukasse M. Fear of birth: prevalence, counselling and method of birth at five obstetrical units in Norway. Women Birth. 2020;33(1):97-104. doi:10.1016/j. wombi.2018.11.008

33. Mortazavi F, Agah J. Childbirth fear and associated factors in a sample of pregnant Iranian women. Oman Med J. 2018;33(6):497505. doi:10.5001/omj.2018.91

34. Toohill J, Creedy DK, Gamble J, Fenwick J. A cross-sectional study to determine utility of childbirth fear screening in maternity practice - an Australian perspective. Women Birth. 2015;28(4):310-316. doi:10.1016/j.wombi.2015.05.002

35. Nieminen K, Stephansson O, Ryding EL. Women's fear of childbirth and preference for cesarean section--a cross-sectional study at various stages of pregnancy in Sweden. Acta Obstet Gynecol Scand. 2009;88(7):807-813. doi:10.1080/00016340902998436

36. Nilsson C, Hessman E, Sjöblom H, et al. Definitions, measurements and prevalence of fear of childbirth: a systematic review. BMC Pregnancy Childbirth. 2018;18(1):28. doi:10.1186/s12884-0181659-7

37. Einarsdóttir EÝ. Pre-test of the Icelandic translation of the measuring instrument CAQ (Childbirth Attitudes Questionnaire). University of Iceland; 2014.

38. Garthus-Niegel S, Størksen HT, Torgersen L, Von Soest T, EberhardGran M. The Wijma delivery expectancy/experience questionnaire: a factor analytic study. J Psychosom Obstet Gynaecol. 2011;32(3):160-163. doi:10.3109/0167482x.2011.573110

39. Steimer T. The biology of fear- and anxiety-related behaviors. Dialogues Clin Neurosci. 2002;4(3):231-249. doi:10.31887/ DCNS.2002.4.3/tsteimer

40. Soltani F, Eskandari Z, Khodakarami B, Parsa P, Roshanaei G. Factors contributing to fear of childbirth among pregnant women in Hamadan (Iran) in 2016. Electron Physician. 2017;9(7):47254731. doi:10.19082/4725

41. Gibbons L, Belizán JM, Lauer JA, Betrán AP, Merialdi M, Althabe F. The global numbers and costs of additionally needed and unnecessary caesarean sections performed per year: overuse as a barrier to universal coverage health systems financing. World Health Rep 2010. 2010;30.

42. Ghazaei M, Davodi I, Neysi A, Mehrabizadeh Honarmand M, Basak Nejad S. Effectiveness of cognitive behavioral therapy and psycho-education on fear of natural childbirth and its related variables. J Appl Psychol. 2018;12(1):103-125.

43. Moher D, Liberati A, Tetzlaff J, Altman DG. Preferred reporting items for systematic reviews and meta-analyses: the PRISMA statement. PLoS Med. 2009;6(7):e1000097. doi:10.1371/journal. pmed.1000097

44. Hasani M, Keramat A, Maasoumi R, Farjamfar M, Yunesian M, Afshar B. The frequency of vaginal intercourse during pregnancy: a systematic and meta-analysis study. Int J Womens Health Reprod 
Sci. 2019;7(1):1-9. doi:10.15296/ijwhr.2019.01

45. Khorasani F, Ghaderi F, Sarbakhsh P, et al. Physiotherapy and Pelvic Floor Muscle Exercises for the Prevention and Treatment of Pregnancy-Related Pelvic Floor Dysfunctions: A Systematic Review and Meta-analysis. Int J Womens Health Reprod Sci. 2020;8(2):125-132. doi:10.15296/ijwhr.2020.20

46. Andaroon N, Kordi M, Ghasemi M, Mazlom R. The validity and reliability of the Wijma delivery expectancy/experience questionnaire (version A) in primiparous women in Mashhad, Iran. Iran J Med Sci. 2020;45(2):110-117. doi:10.30476/ ijms.2019.45326

47. Deliktas A, Kukulu K. Pregnant women in Turkey experience severe fear of childbirth: a systematic review and meta-analysis. JTranscult Nurs. 2019;30(5):501-511. doi:10.1177/1043659618823905

48. Lasheras I, Gracia-García P, Lipnicki DM, et al. Prevalence of anxiety in medical students during the COVID-19 pandemic: a rapid systematic review with meta-analysis. Int J Environ Res Public Health. 2020;17(18). doi:10.3390/ijerph17186603

49. Yan XR, Chen X, Zhang P. Prevalence and risk factors of depression in patients with lung cancer: protocol for a systematic review and meta-analysis. BMJ Open. 2019;9(8):e028994. doi:10.1136/ bmjopen-2019-028994

50. Mildren WG. Prevalence and Risk Factors for Fear of Birth in Pregnant Women in the United States [dissertation]. The University of Texas at Arlington; 2018.

51. Körükcü Ö, Fırat MZ, Kukulu K. Relationship between fear of childbirth and anxiety among Turkish pregnant women. Procedia Soc Behav Sci. 2010;5:467-470. doi:10.1016/j. sbspro.2010.07.125

52. Okumus F, Sahin N. Fear of childbirth in urban and rural regions of Turkey: comparison of two resident populations. North Clin Istanb. 2017;4(3):247-256. doi:10.14744/nci.2017.46693

53. Tata N, Esmaeilpour K, Sehhatti Shafaei F, Mohammadi, Najafzadeh N, Mirghafourvand M. Predictors of fear of childbirth in the primiparous women in Ardabil-Iran. J Clin Diagn Res. 2019;13(7):1-5. doi:10.7860/jcdr/2019/40918.12970

54. Navaie M, Navidian A, Hassanzehi Y, Keykha H. The effect of motivational interviewing on attitude, self-efficacy and decision about type of delivery in primiparus women requesting elective cesarean section referring to comprehensive health services centers of Zahedan in 2018. Zahedan University of Medical Sciences; 2018.

55. Pirdadeh Beiranvand S, Behboodi Moghadam Z, Salsali M, Alavi Majd H, Birjandi M, Bostani Khalesi Z. Prevalence of fear of childbirth and its associated factors in primigravid women: a crosssectional study. Shiraz E Med J. 2017; 18(11):e61896. doi:10.5812/ semj.61896

56. Ternström E, Hildingsson I, Haines H, Rubertsson C. Higher prevalence of childbirth related fear in foreign born pregnant women--findings from a community sample in Sweden. Midwifery. 2015;31(4):445-450. doi:10.1016/j.midw.2014.11.011

57. Sen E, Dal NA, Dağ H, Senveli S. The reasons for delivery: Related fear and associated factors in western Turkey. Nurs Pract Today. 2015;2(1):25-33.

58. Ryding EL, Lukasse M, Parys AS, et al. Fear of childbirth and risk of cesarean delivery: a cohort study in six European countries. Birth. 2015;42(1):48-55. doi:10.1111/birt.12147

59. Erkaya R, Karabulutlu Ö, Çalık KY. Defining childbirth fear and anxiety levels in pregnant women. Procedia Soc Behav Sci. 2017;237:1045-1052. doi:10.1016/j.sbspro.2017.02.151

60. Heimstad R, Dahloe R, Laache I, Skogvoll E, Schei B. Fear of childbirth and history of abuse: implications for pregnancy and delivery. Acta Obstet Gynecol Scand. 2006;85(4):435-440. doi:10.1080/00016340500432507

61. Kjærgaard H, Wijma K, Dykes AK, Alehagen S. Fear of childbirth in obstetrically low-risk nulliparous women in Sweden and Denmark. J Reprod Infant Psychol. 2008;26(4):340-350. doi:10.1080/02646830802408498

62. Mazúchová L, Škodová Z, Kelčíková S, Rabárová A. Factors associated with childbirth-related fear among slovak women. Cent Eur J Nurs Midwifery. 2017;8(4):742-748. doi:10.15452/ cejnm.2017.08.0027

63. O'Connor E, Simpson BS, Houlden H, Vandrovcova J, Matharu M. Prevalence of familial cluster headache: a systematic review and meta-analysis. J Headache Pain. 2020;21(1):37. doi:10.1186/ s10194-020-01101-w

(C) 2022 The Author(s); This is an open-access article distributed under the terms of the Creative Commons Attribution License (http:// creativecommons.org/licenses/by/4.0), which permits unrestricted use, distribution, and reproduction in any medium, provided the original work is properly cited. 